\title{
Endothelial cell damage in human and rabbit corneas stored in K-Sol without antioxidants
}

\author{
T SANJEEVA REDDY, EMILY D VARNELL, ROGER W BEUERMAN, \\ NICOLAS G BAZAN, AND HERBERT E KAUFMAN
} From the Lions Eye Research Laboratories, LSU Eye Center, Louisiana State University Medical Center
School of Medicine, New Orleans, LA 70112, USA

SUMmARY Human and rabbit corneas were stored at $4^{\circ} \mathrm{C}$ in $\mathrm{K}$-Sol with and without antioxidants (ascorbic acid, reduced glutathione, $\alpha$-tocopherol, and retinol acetate) for two to three weeks. All the corneas were then examined visually and by scanning electron microscopy. They appeared clear and slightly oedematous. Scanning electron micrographs were used to grade corneal endothelial cell morphology in a masked manner in terms of cell shape, cell borders, cell swelling, and apical holes. Corneas stored in K-Sol without antioxidants showed changes in cell shape, cell borders, and apical holes. Human corneas showed more morphological changes than rabbit corneas. The results suggest that antioxidants in K-Sol have an important role in the preservation of endothelial cell morphology.

K-Sol corneal preservation medium allows better long-term storage of corneas than storage in McCarey-Kaufman (M-K) medium.1-4 Chondroitin sulphate, the major component of K-Sol, acts as an antioxidant ${ }^{5}$ apart from its role in maintaining osmolality. Lipid peroxides are known to cause considerable damage to membranes by altering their structural and functional components. ${ }^{6}$ Since the maintenance of endothelial cell viability is the most important consideration in long-term preservation of

Correspondence to Professor Roger W Beuerman, LSU Eye Center, 2020 Gravier Street, Suite B, New Orleans, Louisiana, USA. corneas, we have undertaken the present studies to understand the effect of antioxidants in K-Sol on the morphology of endothelial cells.?

\section{Materials and methods}

K-Sol corneal preservation medium was prepared as described previously ${ }^{34}$ or obtained from Cilco, Inc. (Bellevue, Washington). The quantities of antioxidants in K-Sol were as follows: ascorbic acid, 0.28 $\mu \mathrm{M} ; \alpha$-tocopherol phosphate, $0.02 \mu \mathrm{M}$; vitamin A acetate, $0.43 \mu \mathrm{M}$, and reduced glutathione, $0 \cdot 16 \mu \mathrm{M}$. K-Sol without antioxidants was prepared

Table 1 Details of human corneas stored in K-Sol

\begin{tabular}{|c|c|c|c|c|c|c|}
\hline $\begin{array}{l}\text { Age } \\
\text { (years) }\end{array}$ & Cause of death & $\begin{array}{l}\text { Time of } \\
\text { enucleation }\end{array}$ & Eye & $\begin{array}{l}\text { Days stored } \\
\text { in K-Sol } \\
\text { with } \\
\text { antioxidants }\end{array}$ & $\begin{array}{l}\text { Days stored } \\
\text { in K-Sol } \\
\text { without } \\
\text { antioxidants }\end{array}$ & Visual appearance \\
\hline 85 & Vascular insufficiency & $2 \mathrm{hr} 45 \mathrm{~min}$ & $\begin{array}{l}\text { OD } \\
\text { OS }\end{array}$ & $\begin{array}{c}18 \\
3^{*}\end{array}$ & $\overline{15}$ & Clear and slightly oedematous \\
\hline 80 & Acute renal failure & $1 \mathrm{hr}$ & $\begin{array}{l}\text { OD } \\
\text { OS }\end{array}$ & $\begin{array}{c}4^{*} \\
18\end{array}$ & 14 & Clear and slightly oedematous \\
\hline 69 & Renal failure & $2 \mathrm{hr} 15 \mathrm{~min}$ & $\begin{array}{l}\text { OD } \\
\text { OS }\end{array}$ & $\begin{array}{l}16 \\
2 *\end{array}$ & $\overline{14}$ & Clear and slightly oedematous \\
\hline 72 & Respiratory arrest & $11 \mathrm{hr} 52 \mathrm{~min}$ & $\begin{array}{l}\text { OD } \\
\text { OS }\end{array}$ & $\begin{array}{c}4^{*} \\
18\end{array}$ & 14 & Clear and slightly oedematous \\
\hline 40 & Malignant melanoma & $2 \mathrm{hr} 50 \mathrm{~min}$ & $\begin{array}{l}\text { OD } \\
\text { OS }\end{array}$ & $\begin{array}{c}17 \\
3^{*}\end{array}$ & $\overline{14}$ & Clear and slightly oedematous \\
\hline
\end{tabular}

* Received from eye bank in standard K-Sol (with antioxidants) and then transferred to K-Sol without antioxidants in our laboratory. 


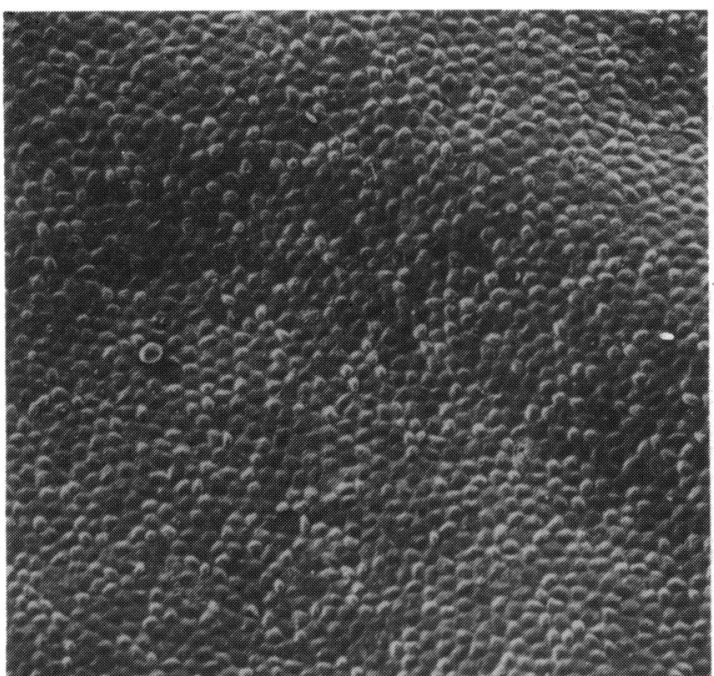

Fig. 1A

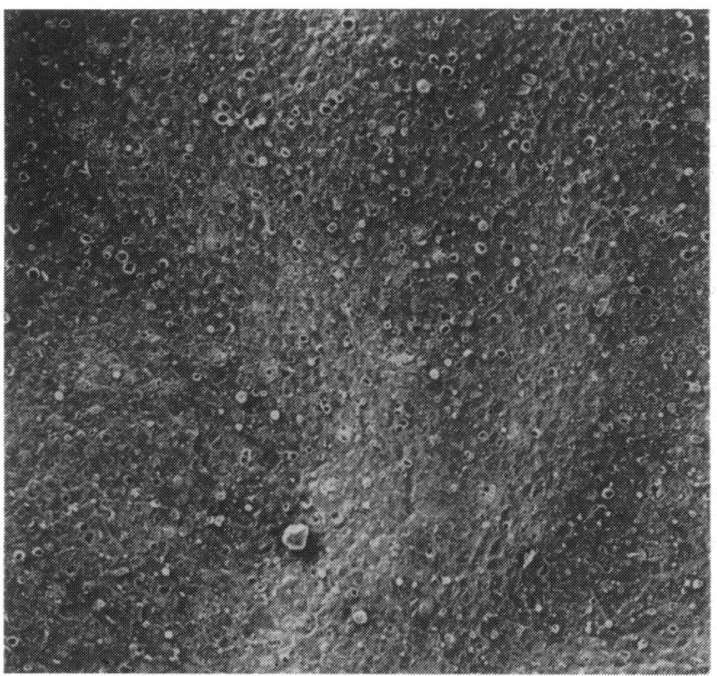

Fig. 1C

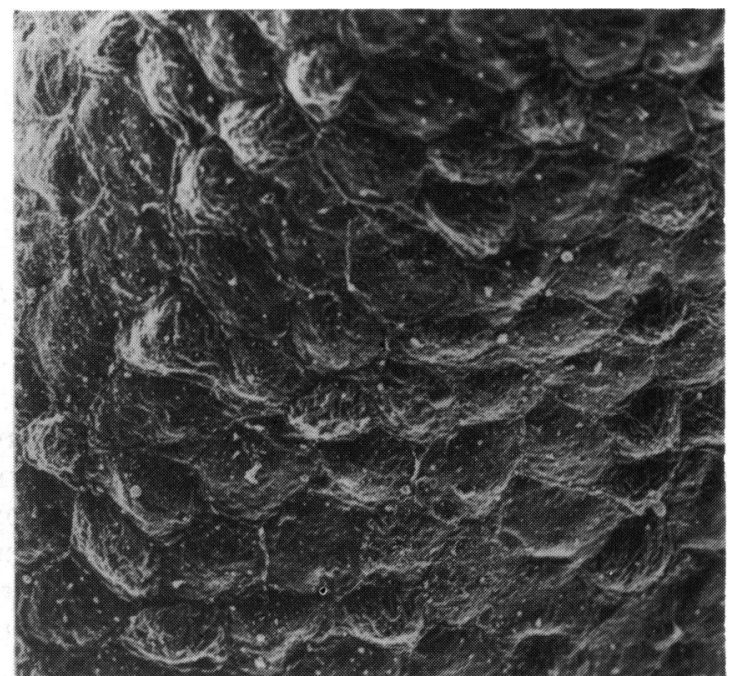

Fig. 1B

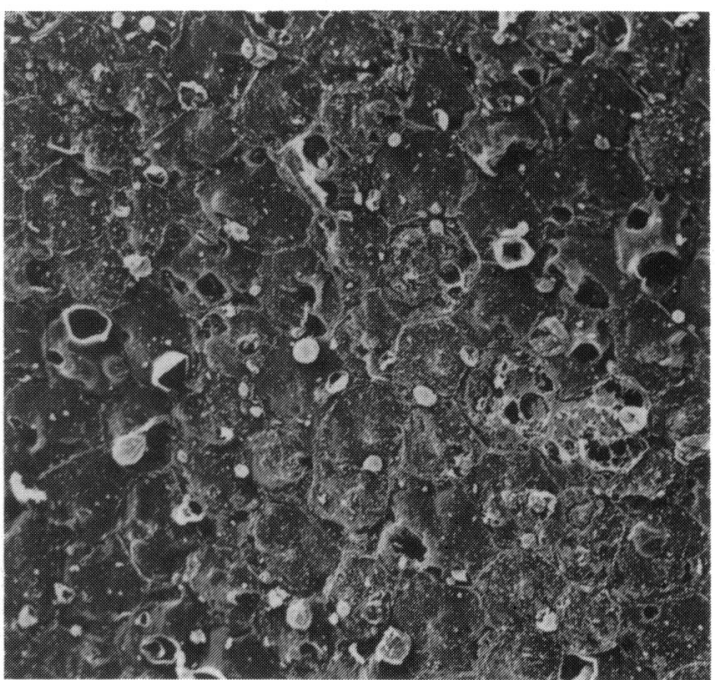

Fig. 1D

Fig. 1 Rabbit corneal endothelial cells after 14 days of storage in K-Sol. Corneas stored in K-Sol with (A and B) and without (C and D) antioxidants ( $\alpha$-tocopherol, ascorbic acid, retinol acetate, and reduced glutathione). (Scanning electron microscopy; $\mathrm{A}$ and $\mathrm{C}, \times 160 ; \mathrm{B}$ and $\mathrm{D}, \times 800)$.

from custom-made medium 199 without ascorbic acid, $\alpha$-tocopherol, retinol acetate, or reduced glutathione (Gibco Laboratories, Grand Island, New York).

Six New Zealand white rabbits weighing 4 to $6 \mathrm{~kg}$ each were used. The rabbits were killed by an overdose of pentobarbital. The eyes were enucleated and washed with normal saline. Corneas with a narrow scleral rim were obtained. The time between the death of the rabbits and the use of the corneas did not exceed 2 hours. The corneas were washed with balanced salt solution and then transferred into $\mathrm{K}$-Sol. One cornea from each rabbit was stored at $4{ }^{\circ} \mathrm{C}$ in $\mathrm{K}$-Sol with antioxidants and the other cornea in $\mathrm{K}$ Sol without antioxidants. Four corneas from each group were removed after 14 days of storage, washed with balanced salt solution, examined visually, and processed for scanning electron microscopy. The 
Table 2 Morphological characteristics of endothelium of corneas stored in K-Sol

\begin{tabular}{|c|c|c|c|c|c|c|c|c|}
\hline Species & $\begin{array}{l}\text { Days of } \\
\text { storage }\end{array}$ & $n$ & Antioxidants & $\begin{array}{l}\text { Cell } \\
\text { shape }\end{array}$ & $\begin{array}{l}\text { Cell } \\
\text { borders }\end{array}$ & $\begin{array}{l}\text { Cell } \\
\text { swelling }\end{array}$ & $\begin{array}{l}\text { Apical } \\
\text { holes }\end{array}$ & $\begin{array}{l}\text { Total } \\
\text { morphological } \\
\text { grade }\end{array}$ \\
\hline \multirow[t]{2}{*}{ Human } & $16-18$ & 5 & + & $1 \cdot 88(0 \cdot 13)$ & $1.50(0 \cdot 00)$ & $1 \cdot 50 \pm 0 \cdot 00$ & $1.75(0 \cdot 14)$ & $1 \cdot 66(0 \cdot 06)$ \\
\hline & $14-15$ & 5 & - & $2.63(0.13)^{*}$ & $3.00(0 \cdot 20)^{*}$ & $1 \cdot 50 \pm 0 \cdot 00$ & $3.50(0.20)^{*}$ & $2 \cdot 66(0.09)^{*}$ \\
\hline \multirow[t]{2}{*}{ Rabbit } & 14 & 4 & + & $1.50(0.20)$ & $1.50(0.00)$ & $1 \cdot 50 \pm 0 \cdot 29$ & $1.50(0 \cdot 20)$ & $1 \cdot 50(0 \cdot 16)$ \\
\hline & 14 & 4 & - & $1 \cdot 83(0 \cdot 17)$ & $2.00(0.00)^{*}$ & $1 \cdot 67 \pm 0 \cdot 17$ & $3 \cdot 33(0 \cdot 17)^{*}$ & $2 \cdot 21(0.11)^{*}$ \\
\hline \multirow[t]{2}{*}{ Rabbit } & 21 & 2 & + & 2.00 & 2.00 & $2 \cdot 00$ & $2 \cdot 50$ & $2 \cdot 13$ \\
\hline & 21 & 2 & - & $3 \cdot 00$ & 3.00 & $2 \cdot 00$ & $3 \cdot 50$ & $2 \cdot 88$ \\
\hline
\end{tabular}

Morphological characteristics of endothelial cells of corneas stored in K-Sol were graded from 1 to 4 using scanning electron micrographs taken from centre of the cornea. Values are mean with standard error of the mean in parentheses. The details of grading are explained in the 'Methods and materials' section. Values marked with asterisks are significantly different from values obtained for corneas stored in K-Sol with antioxidants $(\mathrm{p}<0 \cdot 01$ by Student's $t$ test $)$.

remaining corneas were processed similarly after 21 days of storage.

Five pairs of human corneas were obtained from different eye banks round the country (Table 1). The human corneas had been stored in K-Sol (with antioxidants) by the eye banks for two to four days for preservation during transport. On arrival at the Eye Center the corneas were washed with balanced salt solution. One cornea from each pair was stored in $\mathrm{K}$-Sol with antioxidants and one in K-Sol without antioxidants. The corneas were removed from storage after 14 to 15 days, washed, examined visually, and processed for scanning electron microscopy.

For scanning electron microscopy the corneas removed from K-Sol medium were washed with balanced salt solution and transferred into fixative solution ( $1 \%$ paraformaldehyde and $2.5 \%$ glutaraldehyde in $0.1 \mathrm{M}$ sodium cacodylate buffer, $\mathrm{pH} 7 \cdot 4$ ) and stored at $4^{\circ} \mathrm{C}$ for 3 hours. After further dissection the fixed corneas were incubated in an isotonic buffer solution $(0 \cdot 1 \mathrm{M}$ sodium cacodylate buffer, $0.5 \%$ sucrose) overnight at $4^{\circ} \mathrm{C}$. After postfixation in $1 \%$ osmium tetroxide in $0.1 \mathrm{M}$ sodium cacodylate buffer $(\mathrm{pH} \mathrm{7.4)}$ and ethanolic dehydration, the specimens were further processed for scanning electron microscopy. ${ }^{2}$

Corneal endothelial cell damage was quantified in a masked fashion from scanning electron micrographs of the centre of the cornea at magnifications of $\times 200, \times 500$ and $\times 1000$. A scoring system was used for grading cell shape, cell borders, cell swelling, and apical holes in the cell. Cell shape was graded from 1 (normal hexagonal shape) to 4 (irregular pleomorphic cells). Cell borders were graded from 1 (borders with no irregularities and interdigitations) to 4 (irregular borders with prominent interdigitations). Cell swelling was graded from 1 (flat cells without swelling) to 4 (marked swelling). Apical holes on the endothelial cell surface were graded from 1 to $4: 1,0 \%$ holes; $2,10-20 \%$ holes; $3,40-50 \%$ holes; and $4,70-100 \%$ holes. The mean of the sum of all these measurements was termed the total morphological grade.

\section{Results}

Human and rabbit corneas stored in K-Sol with and without antioxidants for 14 to 21 days were clear but slightly oedematous on visual examination. Rabbit corneas stored in K-Sol without antioxidants for 14 days showed significantly higher numbers of endothelial cell apical holes than corneas stored in K-Sol with antioxidants, as shown by scanning electron micrographs (Fig. 1, Table 2). When the storage was prolonged to 21 days, endothelial cell shape and cell borders were more significantly distorted and apical holes were more numerous in corneas stored in K-Sol without antioxidants than in corneas stored in K-Sol with antioxidants (Fig. 2, Table 2).

Human corneas stored for a total of 16 to 18 days (including transportation time) in K-Sol with antioxidants showed only minor changes in endothelial cell shape, cell borders, swelling, and apical holes (Fig. 3, Table 2). In contrast, human corneas stored for two to four days in K-Sol with antioxidants (during transportation by the Eye Bank), followed by 14 to 15 days in K-Sol without antioxidants in our laboratory, showed significant changes in endothelial cell shape, cell borders, and apical holes (Fig. 3, Table 2).

\section{Discussion}

The present investigation shows that the lack of antioxidants (ascorbic acid, $\alpha$-tocopherol, retinol acetate, and reduced glutathione) in K-Sol results in considerable damage to the endothelial cells. The damage seems to be greater in human corneas than in 


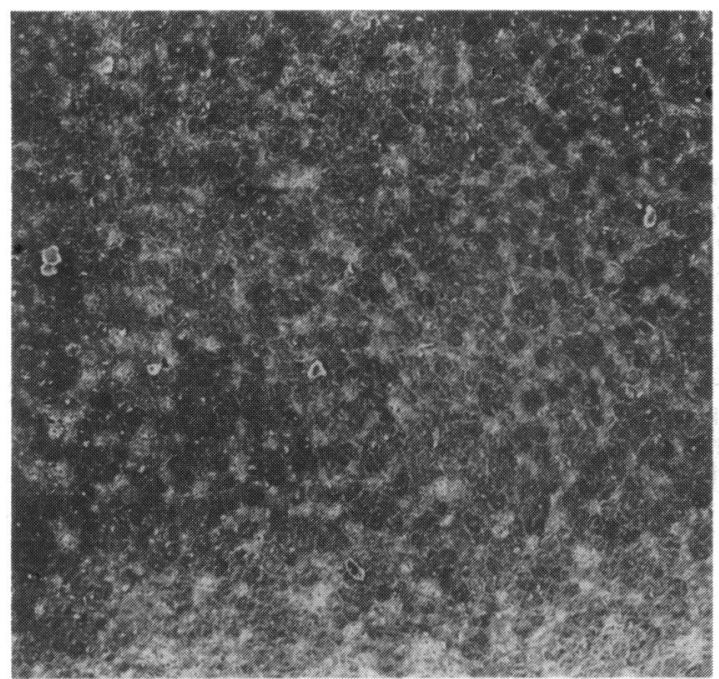

Fig. 2A

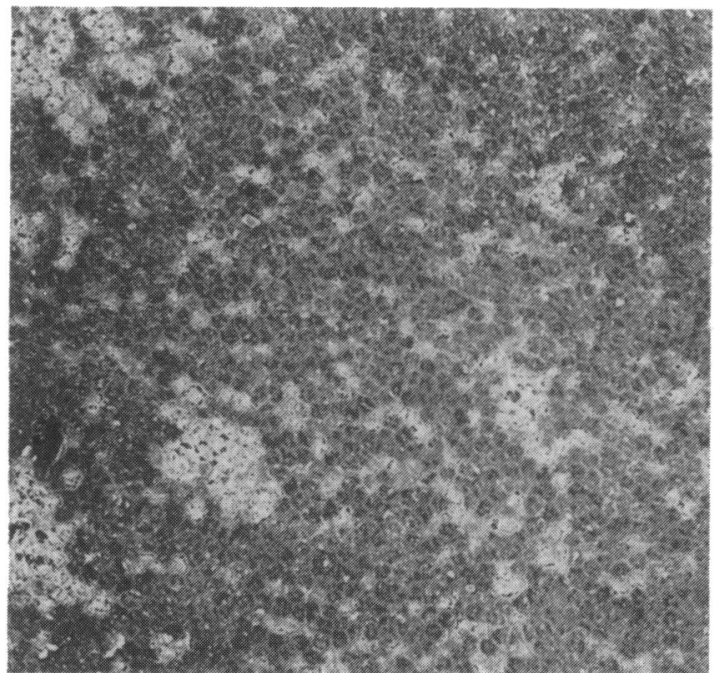

Fig. 2C

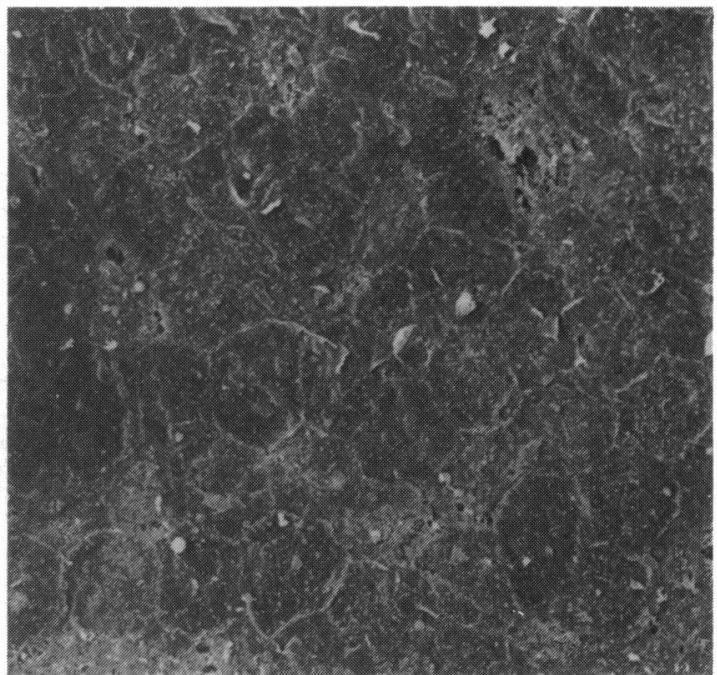

Fig. 2B

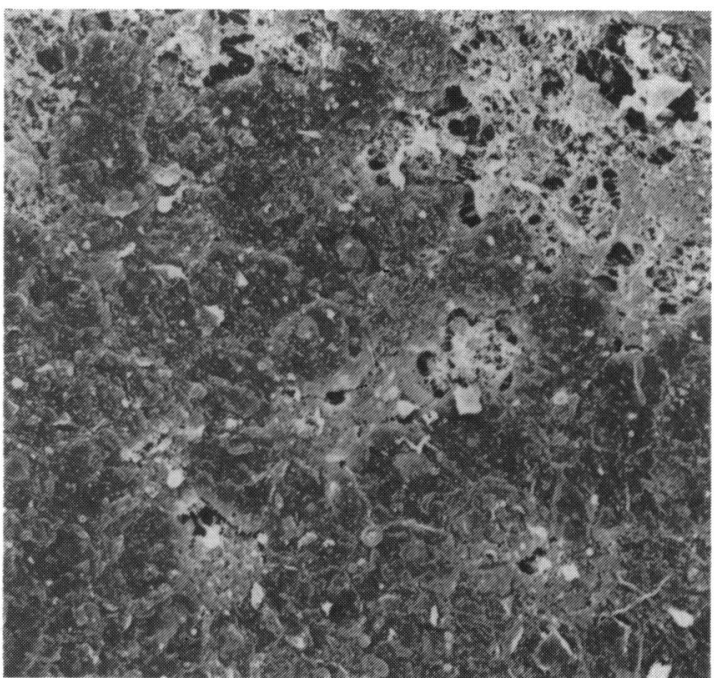

Fig. 2D

Fig. 2 Rabbit corneal endothelial cells after 21 days of storage in K-Sol. A and B: corneas stored in K-Sol with antioxidants $\mathrm{C}$ and D: corneas stored in K-Sol without antioxidants. Scanning electron microscopy: $\mathrm{A}$ and $\mathrm{C}, \times 160): \mathrm{B}$ and $\mathrm{D}, \times 8(0)$.

rabbit corneas. The amount of damage may depend on the levels of antioxidants in individual corneas and the presence of various ions and other metabolites that increase or decrease lipid peroxidation. The levels of antioxidants in K-Sol ( $\alpha$-tocopherol, $0.02 \mu \mathrm{M}$; retinol acetate, $0.43 \mu \mathrm{M}$; ascorbic acid, $0 \cdot 28 \mu \mathrm{M}$; and reduced glutathione, $0 \cdot 16 \mu \mathrm{M}$ ) are low. Recent studies indicate that the concentrations of ascorbic acid ${ }^{x}$ and $\alpha$-tocopherol" required to cause significant inhibition of arachidonic acid oxidation range from $10^{-3}$ to $10^{-4} \mathrm{M}$. Further, the chemical and metabolic fate of added antioxidants in the medium, which may influence the viability of corneal endothelium, is not yet clear. For example, Edelhauser and others" to reduced glutathione in $\mathrm{K}$-Sol is important in maintaining endothelial cell structure and function. Although the levels of glutathione in $\mathrm{M}-\mathrm{K}$ medium 


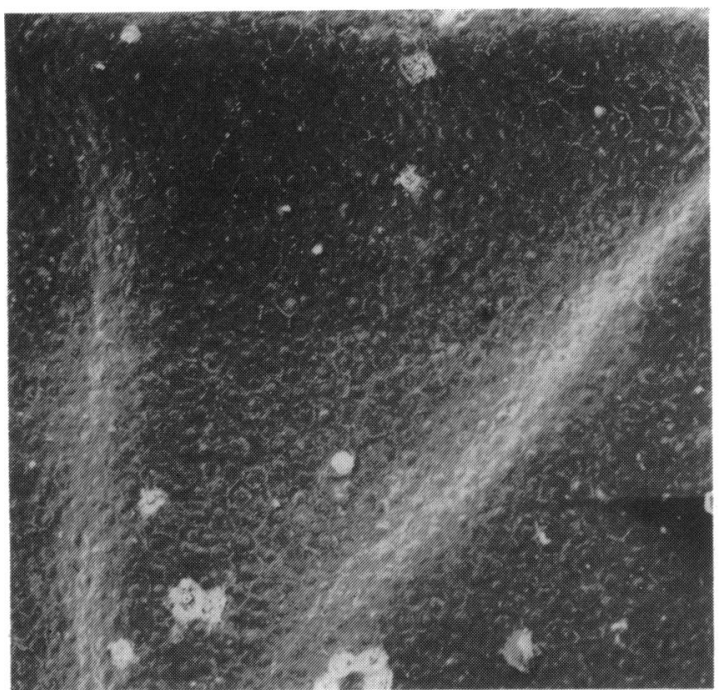

Fig. 3A

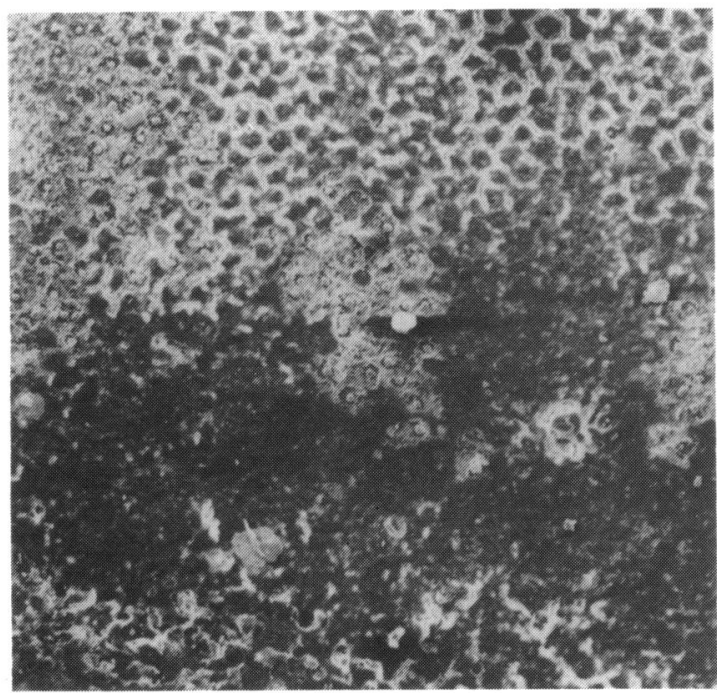

Fig. 3C

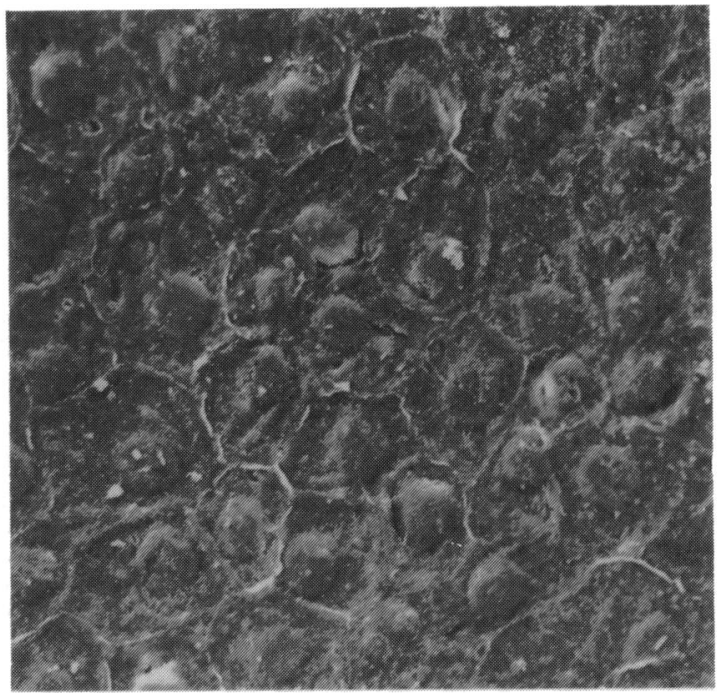

Fig. 3B

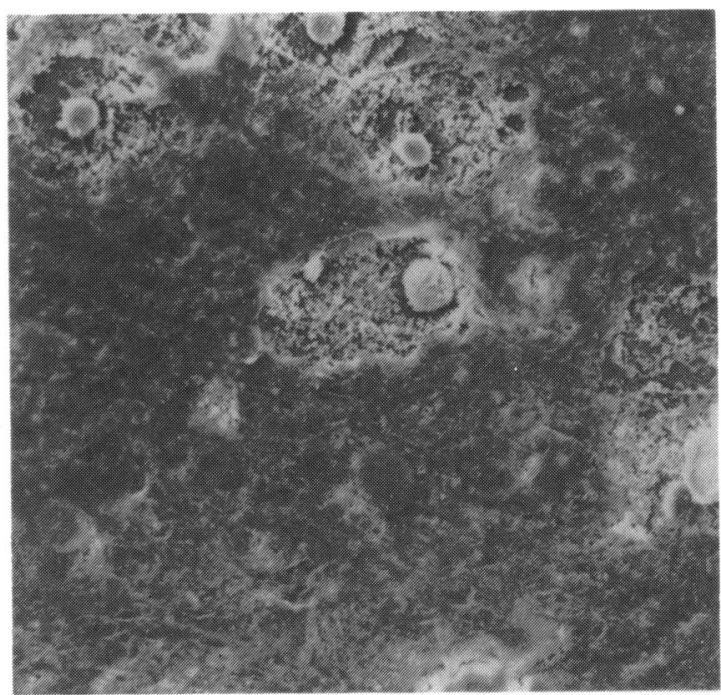

Fig. 3D

Fig. 3 Human corneal endothelial cells after 16 days of storage in K-Sol. The corneas had been stored in K-Sol with antioxidants for two days by the eye banks from which they were obtained. On arrival in our laboratory the corneas were washed and transferred one each into K-Sol with antioxidants (A and $\mathrm{B})$ and $K$-Sol without antioxidants (C and $\mathrm{D})$. The corneas were removed from storage 14 days later and processed for scanning electron microscopy. (A and $\mathrm{C} . \times 160 ; \mathrm{B}$ and $\mathrm{D}, \times 800)$.

were not in the detectable range, the endogeneous levels of glutathione in the endothelium of corneas stored in $\mathrm{M}-\mathrm{K}$ medium did not show significant change over 14 days of storage. " These authors ${ }^{11}$ also reported that the amount of oxidised glutathione, which is toxic to endothelium, decreased from $12.6 \%$ in fresh corneas to $4.0 \%$ in corneas stored in $\mathrm{M}-\mathrm{K}$ medium for 14 days. Since K-Sol contains components essentially similar to those in $\mathrm{M}-\mathrm{K}$ medium, except for the $5 \%$ dextran in $\mathrm{M}-\mathrm{K}$ medium which is replaced with $2.5 \%$ chondroitin sulphate in $\mathrm{K}$-Sol, it is reasonable to assume that most of the glutathione may remain in reduced form.

Although it is clear that antioxidants are necessary 
for the preservation of endothelial cell morphology in corneas stored in K-Sol medium, the relative importance and optimum levels of various antioxidants are not known. Future studies are needed to define the role of particular antioxidants and the optimum levels of these substances to preserve corneal endothelial cells during long-term storage in preserving media such as K-Sol.

This work was supported in part by Public Health Service grants EY(2580, EY04074, and EY(02377 from the National Eye Institute. National Institutes of Health, Bethesda, Maryland.

\section{References}

1 Kaufman HE, Varnell ED, Kaufman S. Chondroitin sulfate in a new corneal preservation medium. Am J Ophthalmol 1984: 93: $112-4$.

2 Kaufman HE, Varnell ED, Kaufman S, Beuerman RW, Barron BA. K-Sol corneal preservation. Am J Ophthalmol 1985: 100: 299-304.

3 Yau C-W, Kaufman HE. A medium-term corneal preserving medium (K-Sol). Arch Ophthalmol 1986: 104: 598-60)1.

4 Busin M. Yau C-W, Avni I, Kaufman HE. Comparison of K-Sol and $\mathrm{M}-\mathrm{K}$ medium for cornea storage: results of penetrating keratoplasty in rabbits. Br J Ophthalmol 1986; 70: 860-3.
5 Trawkin AG. Gundorowa RA. Bordjugowa GG. Erforschung des Zusfundes der Zellmembran und der Mechanismen der Hornhautautolyse bei der Konservierang. Klin Monatshl Augenheilkd 1976: 169: 5(x)-5.

6 Hochstein P. Rice-Evans C. Lipid peroxidation and membrane alterations in erythrocyte survival. In: Yagi K, ed. Lipid peroxides in biology and medicine. New York: Academic Press, 1982: 81-8.

7 Reddy TS, Varnell ED, Beuerman RW, Kaufman HE. Lack of antioxidants in K-Sol medium can cause endothelial cell damage in corneas stored for 2 to 3 weeks. Invest Ophthalmol Vis Sci 1988: 29 (suppl): 113.

8 Williams RN. Paterson CA. Modulation of corneal lipoxygenase by ascorbic acid. Exp Eyc Res 1986; 43: 7-13.

9 Halevy $O$. Sklan D. Inhibition of arachidonic acid oxidation by B-carotene, retinol, and a-tocopherol. Biochim Biophys Acta 1987; 918: 304-7.

10 Edelhauser HF, Van Horn DL, Miller P. Pederson HJ. Effect of thiol-oxidation of glutathione with diamide on corneal endothelial function, functional complex and microfilaments. J Cell Biol 1976: 68: 567-78.

11 Hull DS, Green K. Bowman K. Csukas S, Riley MV. Intracellular $\mathrm{pH}$ and glutathione levels in rabbit corneal endothelium following storage in moist chamber and MK-medium. Inve'st Ophthalmol Vis Sci 1983: 24: 214-7.

Accepted for publication 10 April 1989. 